\title{
Review of the high heat flux testing as an integrated part of W7-X divertor development
}

\author{
H. Greuner ${ }^{\mathrm{a},{ }^{*}}$, B. Böswirth ${ }^{\mathrm{a}}$, J. Boscary ${ }^{\mathrm{a}}$, T. Friedrich ${ }^{\mathrm{b}}$, C. Lavergne ${ }^{\mathrm{a}}$, Ch. Linsmeier ${ }^{\mathrm{a}}$, \\ J. Schlosser ${ }^{\mathrm{c}}$, A.Wiltner ${ }^{\mathrm{a}}$ \\ ${ }^{a}$ Max-Planck-Institut für Plasmaphysik, EURATOM Association, Boltzmannstr. 2, 85748 Garching, Germany \\ ${ }^{b}$ PLANSEE SE, Innovation Services, 6600 Reutte, Austria \\ Association EURATOM-CEA, CEA Cadarache, 13108 St Paul-Lez-Durance, France
}

\begin{abstract}
The subject of the development of the WENDELSTEIN 7-X divertor is the manufacturing of approximately 900 plasma facing components (PFCs) that meet all requirements for reliable long pulse and long-term plasma operation. The actively cooled PFCs are made of CFC NB31 as plasma facing material bonded by Active Metal Casting ${ }^{\circledR}$ (AMC) copper interlayer onto CuCrZr cooling structure. The pre-series activities integrated extensive high heat flux (HHF) testing to assess the industrial manufacturing. Tests were performed in the GLADIS facility under load conditions similar to those expected during operation of W7-X. The investigations focused on the improvement of fatigue resistance of the $\mathrm{CFC} / \mathrm{Cu}$ bonding. The results of the last $\mathrm{HHF}$ test campaign demonstrated a significant enhancement of the CFC bonding quality due to the introduction of the $\mathrm{AMC} / \mathrm{Cu}$ bi-layer technology. The results of the micro-chemical analyses (using EDX, AES, XPS and SIMS) of the CFC/Cu interface performed after 5000 cycles at $10 \mathrm{MW} / \mathrm{m}^{2}$ confirmed its chemical stability. Far beyond the current available data about the expected lifetime of CFC-armoured PFCs, 10,000 cycles at $10 \mathrm{MW} / \mathrm{m}^{2}$ were applied without any damages at the interface. The present design and manufacturing process of the tested PFCs fulfil all requirements for W7-X operation.
\end{abstract}

\section{Introduction}

The development of the WENDELSTEIN 7-X (W7-X) divertor aims to manufacture roughly 900 plasma facing components (PFCs) that fulfil all requirements of reliable long pulse and longterm operation [1]. These nearly $20 \mathrm{~m}^{2}$ of activelywater-cooled PFCs, the so-called targets, are made of CFC NB31 (Snecma Propulsion Solide) as plasma facing material bonded by an Active Metal Casting $\mathbb{\circledR}$ (registered by PLANSEE, AMC) copper interlayer onto a water-cooled $\mathrm{CuCrZr}$ structure [2]. Before launching the serial fabrication, an indispensable part of the pre-series qualification is the high heat flux (HHF) testing of full-scale targets under load conditions similar to those expected during operation. Since 2005, an extensive HHF test program was performed in the HHF test facility GLADIS to evaluate the thermo-mechanical behaviour of the PFCs and to qualify the manufacturing technologies and quality assurance procedures [3]. The investigations were focused to improve the fatigue resistance of the $\mathrm{CFC} / \mathrm{Cu}$ bonding, which was identified as the most critical issue. Modifications of the $\mathrm{CFC} / \mathrm{Cu}$ bonding, e.g. due to variations of the size and orientation of tiles, bonding to the cooling structure by electron beam welding (EBW) or hot isostatic pressing (HIP) were evaluated in the pre-series activities. Based on the experimental data and the numerically computed predictions it was possible to develop a design variation of the interface which was expected to provide a significantly higher reliability of bonding under loading and reasonable manufacturing costs.
The initial $\mathrm{CFC} / \mathrm{Cu}$ bonding was finally modified by the insertion of an additional $\mathrm{Cu}$ interlayer between the $\mathrm{AMC}$ and the cooling structure. This $2 \mathrm{~mm}$ thick soft $\mathrm{Cu}$ layer acts as compliant interlayer and reduces the stress level at the $\mathrm{CFC} / \mathrm{Cu}$ interface to about $50 \%$ [4,5]. A modification of the welding design of the cooling structure by introducing of a central fin increased the stiffness and ensures constant cooling conditions during operation.

The paper summarises the results of the thermo-mechanical evaluation for heat loads ranging between the nominal W7-X design value of $10 \mathrm{MW} / \mathrm{m}^{2}$ and up to the Critical Heat Flux (CHF), with a special focus on the recent high cycle number testing of targets manufactured with the final $\mathrm{CFC} / \mathrm{Cu}$ bonding technique. Results of chemical micro-analysis (using EDX, AES, XPS and SIMS) of the $\mathrm{CFC} / \mathrm{Cu}$ interface performed after high cycle number loading complete the examination.

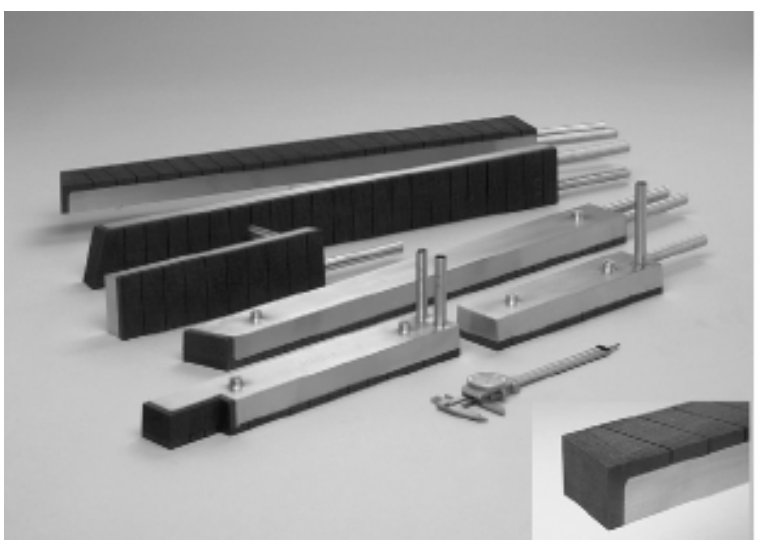

Fig. 1. Pre-series I elements produced by PLANSEE in 2005. The small picture shows the detail of CFC front tile. 


\section{Aims of pre-series manufacturing and HHF testing}

The step from individually manufactured small scale mock-ups to establishing the industrial manufacturing of roughly 900 components up to $0.6 \mathrm{~m}$ length is a scientific and technological challenge. The final design of components has to incorporate all requirements of a reliable and effective manufacturing and has to provide sufficient life time during operation. Hence, an intensive pre-series qualification of full-scale prototypes was performed.

- Pre-series I: Manufacturing of the most difficult types of target elements. The HHF testing aimed at verification of the thermomechanical behaviour of the different types of targets, and particularly to investigate the performance of CFC front tiles $(66 \%$ of target elements are protected with CFC front tiles) [3]. Fig. 1 shows the different types of target elements.

- Pre-series II: An additional step was needed due to the production of CFC material that not fully met the specification [6]. A set of 20 "standard elements" $(250 \mathrm{~mm}$ length, $57 \mathrm{~mm}$ width, covered with 10 CFC flat tiles and no CFC front tile) was manufactured. The evaluation was focused on the qualification of EBW or HIP as joining technique between AMC layer and $\mathrm{CuCrZr}$ structure. - Pre-series III: The results of the previous pre-series showed that CFC can be accepted by IPP but the percentage of defective tiles after HHF testing was too high to launch the serial fabrication. Based on the results of 3D non-linear thermo-mechanical FEM analyses focused on the $\mathrm{CFC} / \mathrm{Cu}$ interface, an additional set of 17 standard elements including three design variations was investigated to select the final manufacturing route. The HHF test results confirmed the predicted significantly higher reliability of CFC bonding due to the insertion of an additional compliant copper interlayer (so called bi-layer) between the cooling structure and the AMC interlayer [5].

- Pre-series IV: As final evaluation of the series production techniques, a set of 10 standard elements was manufactured and successfully tested. The following improvements were implemented in the final design:

- $\mathrm{CFC}$ bonding made by AMC/Cu bi-layer (a micrograph of crosssection of $\mathrm{CFC} / \mathrm{Cu}$ bonding of bi-layer type is published in [5]). - EBW of bi-layer tiles to the cooling structure.

- Optimised welding design of the cooling structure to ensure a reliable heat removal during operation.

\section{High heat flux tests}

\subsection{Heat loading conditions in GLADIS}

The GLADIS test conditions were similar to the W7-X full power operating requirements: $8 \mathrm{~m} / \mathrm{s}$ cooling water velocity, $\sim 20 \circ \mathrm{C}$ inlet temperature and $1 \mathrm{MPa}$ static pressure. The target elements were mounted perpendicular to the ion beam axis in the GLADIS facility, except for the tests of front tiles. Due to the Gaussian beam profile of the hydrogen beam, three test positions were necessary to load the standard targets with a uniform heat flux on each tile. A typical pulse length of $10 \mathrm{~s}$ per cycle was applied, because the target achieved the thermal equilibrium after $7 \mathrm{~s}$ of loading. For the surface temperature measurements an IR camera and one- and twocolour pyrometers were used. The component temperature was measured with thermocouples (type K) positioned within the cooling structure and the CFC tiles. A detailed description of the beam profiles, the used diagnostics and the thermocouple positions is given in [7].

\subsection{Results and discussion of low cycle fatigue loading of $10.5 \mathrm{MW} / \mathrm{m}^{2}$}

The technical specification of the target elements requires after loading with 100 pulses $10 \mathrm{MW} / \mathrm{m}^{2}$ each for $10 \mathrm{~s}$ : no visible degradation of the $\mathrm{CFC} / \mathrm{Cu}$ bonding or growing hot spots on the loaded surface. A good assessment of the $\mathrm{CFC} / \mathrm{Cu}$ bonding quality is given by IR analysis of local temperature differences between tile centre $T_{\text {centre }}$ and the outer edges $T_{\text {edge }}$ in the steady-state condition for each pulse. The evolution of local temperature differences $\Delta T_{N}=\left(T_{\text {edge }}-T_{\text {centre }}\right) N-\left(\text { Tedge }_{\text {ed }}-T_{\text {centre }}\right)_{1}$ after $N$ cycles allows a reliable detection of growing defects. This parameter of IR analysis taken in the steady-state phase of each pulses reduces the influence of steady CFC inhomogeneities to the interpretation. A temperature increase $\Delta T_{N} \leq 50 \mathrm{~K}$ for an adequate, of $\Delta T_{N}=50-75 \mathrm{~K}$ for a questionable and $\Delta T_{N}>75 \mathrm{~K}$ for an inadequate bonding was applied as preliminary assumption. These criteria are based on the experiences of crack propagation for up to 5000 cycles, thermal FEM simulations of different types and sizes of bonding defects and the given optical resolution of the IR camera. A questionable bonding requires further investigations before such a target can be accepted. Table 1 summarises the classification results for all tested pre-series elements and $N=100$ cycles. The data interpretation of the criterion $\Delta T_{N}$ after $N=100$ cycles of the CFC tiles is the basis of a statistical validation of the manufacturing process in order to minimise the manufacturing risks and the rejection rate. The detailed comparison between pre-series III and IV in percentage of $5 \mathrm{~K}$ temperature steps shows the significant progress of $\mathrm{CFC}$ bonding in the final design (Fig. 2).

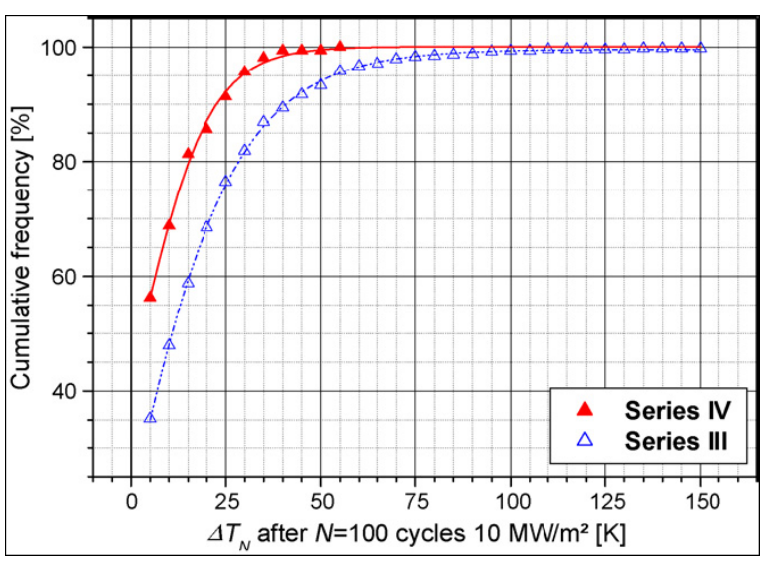

Fig. 2. Statistical validation of the increase of the CFC surface temperature during $10 \mathrm{MW} / \mathrm{m}^{2}$ loading due to growing bonding defects. The comparison based on 80 analysed CFC tiles of series IV and 261CFC tiles of series III. A perfect bonding resulted in $\Delta T \leq 50 \mathrm{~K}$ after 100 cycles at $10 \mathrm{MW} / \mathrm{m}^{2} . \Delta T \geq 75 \mathrm{~K}$ indicates small, however visible, defects at the $\mathrm{CFC} / \mathrm{Cu}$ bonding.

\subsection{HHF tests with increased heat loads}

In addition to the nominal heat load $\leq 10 \mathrm{MW} / \mathrm{m}^{2}$ stationary, the targets must allow for a limited operation time at $12 \mathrm{MW} / \mathrm{m}^{2}$ stationary and should not fail during transient pulses up to 15 $\mathrm{MW} / \mathrm{m}^{2}$ [8]. A critical heat flux $\geq 25 \mathrm{MW} / \mathrm{m}^{2}$ is specified. In order to evaluate the target performance for heat loads exceeding the nominal heat flux, different test campaigns were performed. Table 2 summarises the most important results. Tests were performed with a load of $20 \mathrm{MW} / \mathrm{m}^{2}, 3 \mathrm{~s}$, for 1000 cycles to investigate the strongly increasing thermo-mechanical stresses in the CFC bonding during transient overloading. However, the corresponding surface temperature of $1600^{\circ} \mathrm{C}, 500{ }^{\circ} \mathrm{C}$ above the nominal temperature, should be easily detectable to avoid a high number of such events during operation of W7-X. For comparison, during $10 \mathrm{MW} / \mathrm{m}^{2}$ nominal loading a surface temperature increase of $500 \mathrm{~K}$ is based on a $\mathrm{CFC} / \mathrm{Cu}$ debonding size of $>50 \mathrm{~mm}^{2}$. The tested pre-series IV element survived these loading conditions without visible damages. 
Table 1

Classification of $10 \mathrm{MW} / \mathrm{m}^{2}$ low cycle fatigue tests of $\mathrm{CFC} / \mathrm{Cu}$ bonding variants.

\begin{tabular}{|c|c|c|c|c|c|c|}
\hline Pre-series & CFC/Cu bonding & Elements tested & CFC tiles tested & Adequate bonding & Questionable bonding & Inadequate bonding \\
\hline I & AMC, EBW or HIP & 7 & 87 & $54 \%$ & $22 \%$ & $24 \%$ \\
\hline II & AMC, EBW or HIP & 20 & 209 & $70 \%$ & $15 \%$ & $15 \%$ \\
\hline III & AMC, bi-layer, EBW or HIP & $17^{2}$ & 261 & $87 \%$ & $8 \%$ & $5 \%$ \\
\hline IV & Bi-layer, EBW & 10 & 80 & $99.4 \%$ & $0.6 \%$ & - \\
\hline
\end{tabular}

The implementation of the bi-layer bonding resulted in a significant better reliability of CFC tile bonding.

${ }^{\text {a }}$ Summary of all design options. A detailed analysis is presented in publication [5].

Table 2

Summary of performed HHF testing with increased power loads.

\begin{tabular}{lccl}
\hline & Design value $\left(\mathrm{MW} / \mathrm{m}^{2}\right)$ & Achieved value $\left(\mathrm{MW} / \mathrm{m}^{2}\right)$ & Remarks \\
\hline CFC front tiles & 2 & 3.5 & Average value [3] \\
Standard tiles, cycling 50-100 pulses, 6 elements & 12 & 13.5 & Limited pulse numbers requested [6] \\
Standard tiles, cycling 1000 pulses 3s & 15 & 20 & Simulation of transient overloading \\
Standard tiles, screening & 15 & 24 & CFC/Cu interface temp. Close to melting [9] \\
Critical heat flux (CFC armour removed) & 25 & 31 & Standard element [9] \\
\hline
\end{tabular}

Pulses of $10 \mathrm{MW} / \mathrm{m}^{2}, 15 \mathrm{~s}$, were applied before and after the test campaign to evaluate a possible degradation of the CFC bonding. The cyclic loading of $20 \mathrm{MW} / \mathrm{m}^{2}$ for 1000 cycles resulted in a surface temperature increase between 60 and $120 \mathrm{~K}$ in the centre and at the outer edges of central tiles. Neighbouring tiles receiving $\leq 15 \mathrm{MW} / \mathrm{m}^{2}$ did not show any temperature increases during cycling.

\subsection{Results of extended heat loading up to 10,000 cycles}

After the test of two pre-series III elements with $10 \mathrm{MW} / \mathrm{m}^{2}, 10 \mathrm{~s}$, for 5000 cycles [5], one element of the pre-series IV was tested up to 10,000 cycles. According to the loading conditions in GLADIS, three CFC tiles were loaded with $10 \mathrm{MW} / \mathrm{m}^{2}$, and 4 tiles with 7-9 $\mathrm{MW} / \mathrm{m}^{2}$. During the cycling of pre-series III three minor bonding defects occurred, whereas the pre-series IV element survived the 10,000 cycles without any detectable defects. Fig. 3 shows comparable IR images of the cycles \#20 and \#10,000. The visual inspection of the $\mathrm{CFC} / \mathrm{Cu}$ bonding did not reveal any cracks or CFC delaminations. The evolution of the measured temperature at different locations of the elements is shown in Fig. 4. The steady temperature of the cooling structure $(\Delta T$ cycling $=6 \mathrm{~K})$, the marginal temperature increase of CFC tile (thermocouple located 4 $\mathrm{mm}$ above the $\mathrm{Cu}$ bonding, end temperature $770{ }^{\circ} \mathrm{C}, \Delta T$ cycling $=$ $70 \mathrm{~K}$ ) and the surface temperature (pyrometrically measured end temperature $1122^{\circ} \mathrm{C}, \Delta T$ cycling $=40 \mathrm{~K}$ ) confirm the suitability of the tested target design for long-term operation.

\section{Micro-chemical analysis of the $\mathrm{CFC} / \mathrm{Cu}$ interface}

Thermally induced mechanical stress at the $\mathrm{CFC} / \mathrm{Cu}$ interface is most critical with respect to lifetime predictions of the components. Besides mechanical reasons, also new chemical compounds formed at the interface by heat loads during operation can lead to additional stress. In particular, possible carbides formed during cycling would change the mechanical properties and enhance the brittleness of the interface. In order to confirm the chemical stability of the AMC interface close to the CFC after long-term loading and to improve the understanding of the mechanism of crack propagation, a comparative micro-chemical analysis of the interface was performed on samples with different load cycle numbers.

Besides a practically unloaded sample (S0, one pulse of $8 \mathrm{MW} / \mathrm{m}^{2}$ only), samples which received 1000 (S1000) and 5000 pulses (S5000), respectively, of $10 \mathrm{MW} / \mathrm{m}^{2}$ for $10 \mathrm{~s}$, were investigated. The metallographic cross-sections were prepared from cuts of the targets perpendicular to the length axis. First of all, optical microscopy of the samples was performed to count the number of fissures in the $\mathrm{CFC} / \mathrm{Cu}$ interface across the target width. The result is: 90 fissures in S0, 60 fissures in S1000 and 15 fissures in S5000 only. This result confirms the assumption that a CFC-covered PFC has to operate with numerous initial fissures due to the intrinsic inhomogeneity of the CFC.
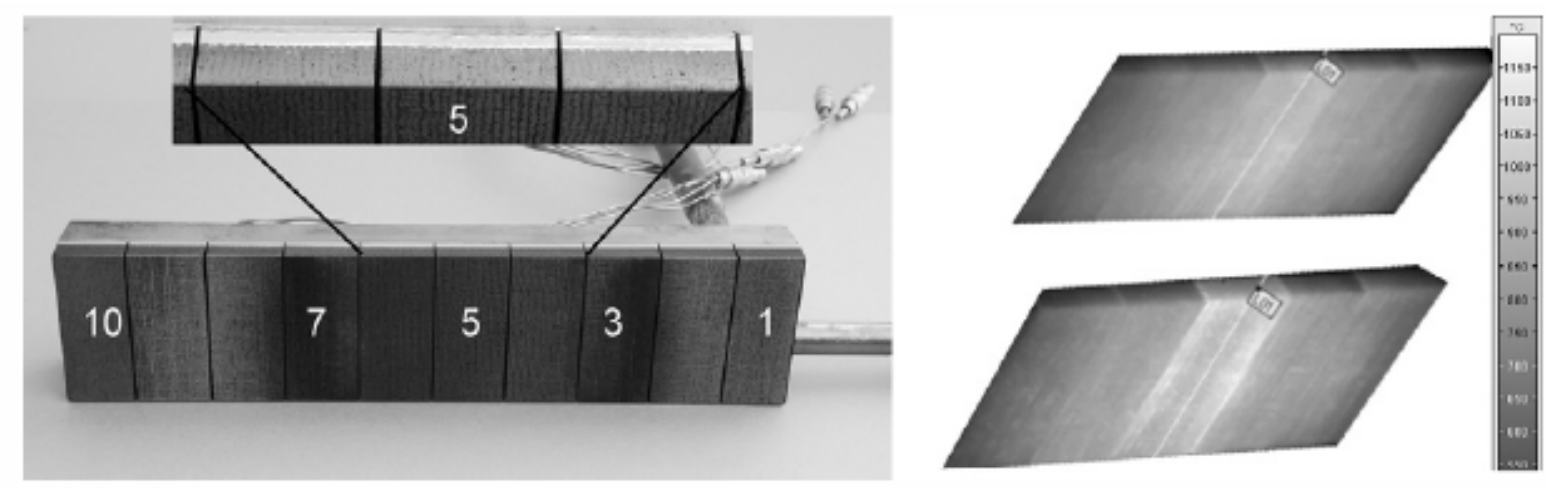

Fig. 3. Pre-series IV element after loading $10 \mathrm{MW} / \mathrm{m}^{2} \times 10,000$ cycles. Beam centre was placed on tile 5. Right hand side: upper image shows an IR image of tiles 7-2 during cycle \#20, lower images correspond to cycle \#10,000. 


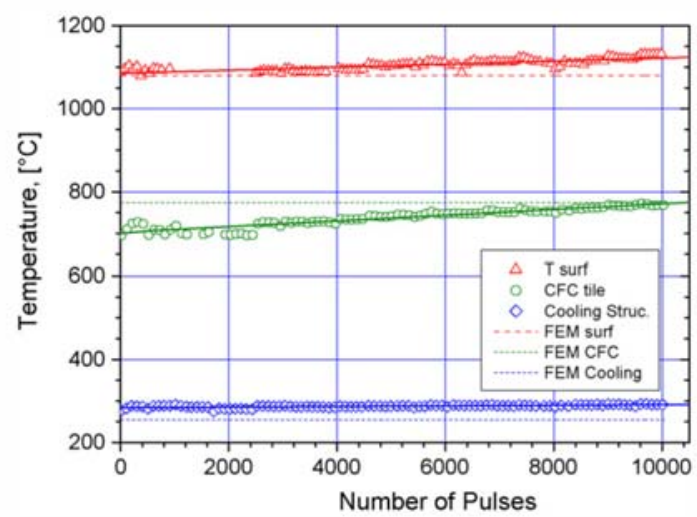

Fig. 4. Measured temperatures in the centre of component during 10,000 cycles $10 \mathrm{MW} / \mathrm{m}^{2}, 10 \mathrm{~s}$. The graph shows the pyrometrically measured surface temperature and the corresponding temperatures of CFC tile and cooling structure both from thermocouples for each pulse. The dashed lines mark the expected temperatures obtained from FEM calculation.
These fissures are generated due to the high residual stress after manufacturing and did not heal during operation $\left(10 \mathrm{MW} / \mathrm{m}^{2}\right.$ loading resulted in a $\mathrm{CFC} / \mathrm{Cu}$ interface temperature of $<500{ }^{\circ} \mathrm{C}$ ). The design of the $\mathrm{CFC} / \mathrm{Cu}$ interface, depending on geometry, materials, loading and cooling conditions, etc., has to minimise the probability of crack propagation of such incipient cracks. The characterisation of AMC close to CFC using EDX line scans across the layer confirms the expected material composition. $\mathrm{Cu}, \mathrm{Ti}, \mathrm{Si}$ and $\mathrm{C}$ were identified in similar concentrations on all samples. AES analysis and SIMS sputter depth profiles of a $100 \mu \mathrm{m} \times 100 \mu \mathrm{m}$ area up to a depth of $1 \mu \mathrm{m}$ confirmed the chemical composition determined by EDX. Samples S0 and S5000 were further investigated by XPS. This method determines the chemical compounds, and in particular can quantify the amount of carbides. Emphasis was placed on $\mathrm{TiC}$ and Ti subcarbides. Analysis of the intensities in the $\mathrm{Ti} 2 \mathrm{p}, \mathrm{C} 1 \mathrm{~s}$, and $\mathrm{Cu} 2 \mathrm{p}$ binding energy regions result in 5-6 at.\% of carbidic carbon (both $\mathrm{TiC}$ and $\mathrm{Tix} \mathrm{Cy}$ ) in the unloaded sample $\mathrm{S} 0$ and 9 at.\% in sample S5000. The $\mathrm{C} 1 \mathrm{~s}$ high resolution photoelectron spectra (Fig. 5a and b) show as main contribution elemental carbon (graphitic and disordered graphitic peaks), and the $\mathrm{TiC}$ and Ti subcarbide peaks. Despite the high thermal load of 5000 cycles, the carbidic peaks increase only to 9 at. $\%$, compared to the 5-6 at.\% in the unloaded state.

\section{Conclusions}

The assessment of the industrial manufacturing of PFCs requires extensive HHF tests as integrated part of pre-series activities. The pre-series IV resulted in an important step in the establishment of the industrial manufacturing process. The amount of CFC tiles without any indications of bonding defects after HHF test loading
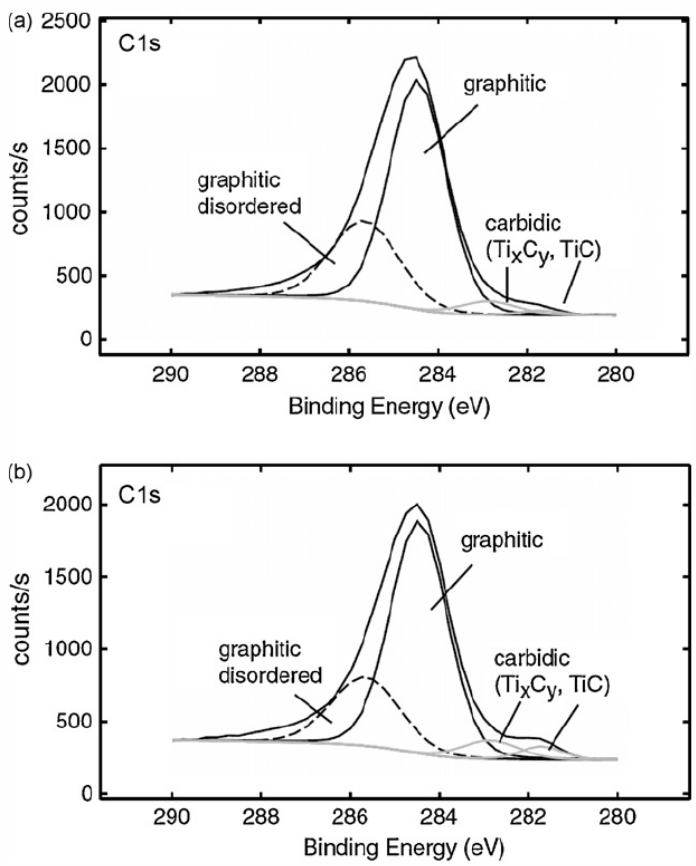

Fig. 5. ( $a$ and $b$ ) C 1s signals of the XPS analysis of AMC layer close to the CFC. The unloaded sample SO (a) shows slightly lower intensities of the carbidic carbon signals TixCy and TiC, compared to the sample S5000, after 5000 loading cycles.

performed at $10 \mathrm{MW} / \mathrm{m}^{2}$ and 100 cycles achieved $99.4 \%$ in preseries IV. This significant enhancement of the bonding performance is mainly due to the introduction of the bi-layer manufacturing process used for the pre-series IV elements covered with standard CFC tiles fulfil all W7-X requirements for long pulse and long-term operation.

\section{References}

[1] H. Renner, J. Boscary, V. Erckmann, H. Greuner, H. Grote, J. Sapper, et al., The capabilities of steady state operation at the stellarator W7-X with emphasis on divertor design, Nucl. Fusion 40 (2000) 1083-1093.

[2] J. Boscary, H. Greuner, B. Mendelevitch, B. Schedler, K. Scheiber, J. Schlosser, B. Streibl, Applied technologies and inspections for the W7-X pre-series target elements, Fusion Eng. Des. 75 (79) (2005) 451-455. [3] H. Greuner, B. Boeswirth, J. Boscary, P. McNeely, High heat flux facility GLADIS: operational characteristics and results of W7-X pre-series target tests, J. Nucl. Mat. 367 (370) (2007) 1444-1448.

[4] A. Plankensteiner, A. Leuprecht, B. Schedler, K.-H. Scheiber, H. Greuner, Finite element based design optimization of WENDELSTEIN 7-X divertor components under high heat flux loading.

[5] H. Greuner, B. Böswirth, J. Boscary, P. Chaudhuri, J. Schlosser, T. Friedrich, A. Plankensteiner, R. Tivey, Cyclic Heat Load Testing of Improved CFC/Cu Bonding for the W 7-X Divertor Targets, J. Nucl. Mat. 386-388 (2009) 772-775

[6] J. Boscary, B. Böswirth, H. Greuner, M. Missirlian, B. Schedler, K. Scheiber, J. Schlosser, B. Streibl, Results of the examinations of the W7-X pre-series target elements, Fus. Eng. Design 82 (2007) 1634-1638. 